\title{
A New Framework for Online Business Teaching
}

\author{
Cristina Nistor, Prashanth Nyer \\ Chapman University, Orange, California, USA \\ Email: nistor@chapman.edu, nyer@chapman.edu
}

How to cite this paper: Nistor, C. and Nyer, P. (2018) A New Framework for Online Business Teaching. Open Journal of Business and Management, 6, 576-584. https://doi.org/10.4236/ojbm.2018.63044

Received: March 31, 2018

Accepted: June 4, 2018

Published: June 7, 2018

Copyright $\odot 2018$ by authors and Scientific Research Publishing Inc. This work is licensed under the Creative Commons Attribution International License (CC BY 4.0).

http://creativecommons.org/licenses/by/4.0/

\begin{abstract}
Recently, business education has experienced an expansion of online education programs. In this paper, we propose a framework to improve the effectiveness of student learning in an online lecture format. In particular, we focus on business courses, which tend to be hard to replicate online as they rely on team work and applied logical thinking in addition to the learning of facts and theory. We identify two main areas that are vital to online business education: competition and community building among students. We argue these are an additional task for the instructor to deliberately perform in an online setting, compared to what often occurs organically in a traditional in-class setting.
\end{abstract}

\section{Keywords}

Online Education, Business Education, Online Courses, Education Platforms

\section{Introduction}

Online teaching has recently increased in popularity within business schools in North America. Some of the top business schools programs are now offering online courses and some of the best undergraduate colleges actually offer online bachelor's and master's degrees. For example, BestSchools.org ranks Penn State, University of Florida, University of Massachusetts, Boston University and Northeastern University as their top five picks for online education, with more top universities being listed in their top 100 list of schools with online programs [1]. Similarly, for online MBA programs, schools that are traditionally strong in offering rigorous MBA programs have now also developed a strong reputation for online education. The top five in the "Top 50 online MBA programs" include prestigious schools such as University of North Carolina-Chapel Hill, Indiana University, University of Maryland-College Park, Arizona State University, and Penn State World Campus [2]. 
Highly motivated students value the flexibility of online learning. Many students work internships to help their careers [3] or have part-time or full-time jobs to earn money to pay for their education, especially as educational loans take a larger portion of overall debt. The WSJ reported that a total of 40 million Americans have student loan debt, with a total outstanding debt of 1.4 trillion dollars as of 2014 [4]. In the context of rising debt, online MBA programs or business related masters programs offer an attractive solution to students who are faced with the doubly troubling problem of costly undergraduate degrees with limited income earning potential, and more debt coming from a potentially lucrative, but time consuming graduate degree.

Online courses vary widely depending on the institution and degree they are part of. In this paper, we focus on courses that are online and offered by highly regarded institutions. These range from small classes offered by private institutions to large cohort courses offered by state universities. In addition, our analysis is not restricted to courses that are paid: our framework applies to classes that can cost quite a bit if they are used as part of a degree offered by a private university, includes lower cost classes offered by state universities and even includes massive open online classes offered for free by top research universities (MOOCS). The universe of online classes and degrees has evolved in the last decade into a rich and vibrant educational ecosystem.

In this paper, we develop a framework for online business education. We identify two main components that would develop organically in an in-class teaching setting but which would need to be specifically and carefully designed and facilitated online by the instructor: community and competition among the students. We present examples of how to create these learning experiences and also suggest directions for further study.

\section{Literature}

Online education for business classes has been a topic of interest for business educators for the past few decades. The literature has ranged from investigating how online platforms can be used in traditional platforms [5] to how to best structure remote web conferencing in teams [6]. Online platforms such as Blackboard or Canvas were first started to share class materials for traditional classes. Hollenbeck et al. [5] identified the necessary components for online platforms in this context, with a specific application to marketing students: the paper focused on student learning satisfaction and outcomes. Our paper extends this stream of literature by focusing on all-online classes, where all the materials are shared on learning platforms. We identify the components of online education that need to be re-created online by the instructor.

Recent work on remote teams that work and collaborate online has focused on the effects that such online collaborations may have on learning outcomes and student satisfaction. Giesbers et al. [6] found, surprisingly, that teams that are able to communicate via web-conferencing software did not report better satis- 
faction with the learning process. The advances in recent, better technology may have improved the ease with which students use web-conferences (for example, Zoom is much easier and more intuitive to use now than anything available in 2008) but it is still the case that face-to-face interactions seems to be preferred and web-conferences are necessary but not a perfect substitute for in-person meetings. Moreover, the business world is struggling to understand this phenomenon in the related setting of having employees who work-from-home. There is some evidence that creativity can be enhanced through in-person interactions; however this would result in reduced work schedule flexibility for those involved. Moreover, it seems that students may intuitively prefer to supplement online learning with more traditional in-class lectures and meetings [7].

More recent literature in online marketing education has also considered the use of social media interactions as a way to simulate face-to-face interactions [8]. The findings indicate that a blend of social media and face-to-face meetings lead to greater student collaboration and satisfaction. We use this stream of research to theorize on why face-to-face interactions are important and formulate the framework in the current paper.

Our paper introduces concepts related to collaborative learning, which has been studied extensively in the education and technology literature [9]. Collaborative learning, the practice of having students learn concepts in small groups in person rather than through a lecture, has been shown to have effects on deep learning and critical thinking ([10] [11] etc.). Peer collaboration assisted by modern collaboration technologies (as in [12] for example) is similarly related to our theory. In our paper, we develop the concept of community learning, which is not as restrictive as collaborative learning, and does not require that students work in groups but rather be able to learn as a positive externality from being around other students who ask interesting questions, may explain concepts better, and just generally be more engaged by hearing the same concepts repeated several times from different perspectives.

Our paper is also related to peer pressure learning effects summarized in [13] in that we consider competition learning to be a type of peer pressure learning, where the students are incentivized to learn more because they can see other students learning.

In our recommendations, our paper is also building on the literature that finds that individualized assessments of students tend to inhibit peer learning and deliver lower rates of critical thinking [14]. In business schools, and even more so in online business classes, our framework suggests that the current practice of evaluating students on their individual, non-collaborative deliverables is hindering learning.

\section{Theory Framework}

The online education environment has evolved into a complex system that delivers education information to students. A simplified depiction of the online 
education system is represented in Figure 1.

We created Figure 1 as a stylized visual representation of the ecosystem that surrounds online education. Rather than describing one particular institution or degree, Figure 1 illustrates the process and the stakeholders who control the online education courses in many universities in North America.

The main decision maker of the online education system is the Office of Online Education, which can be housed under various names in different universities. For example, in some universities, it may be housed under a separate department for online education [15] [16] which is then supported by various centers and departments in the larger university or college setting, like Teaching and Learning Center, IT staff, Disabilities Office.

Despite the different names or departments that may house the online education classes and degree, each school usually dedicates one office (which we generally call "Online Education") that coordinates the learning platform, decides which applications will be available on the platform and perhaps has input on the classes taught and the criteria for students admitted in the program. The office of online education also coordinates online testing, set rules for in-class exams, and resolve other problems that may impact the population of students engaged in distance learning. For example, if some students are affected by a hurricane because they live in an area that has weather disasters, then the office will coordinate how the university will respond in terms of examinations and delivering teaching materials, even if the main physical campus may not be affected by the same disaster.

Technological advancements have made conveying information, remote group collaborations, and remote testing possible. Online Learning Platforms like Canvas or Blackboard can now incorporate third party Education Add-ins like ProctorU (for proctored testing) or GoReact (for presentations of students work) or YellowDig (for social media like postings and discussions). These harness the potential of technology to rival in-class learning and testing experiences while also helping students take control of their schedules and achieve more with their time.

However, as rich as the potential learning experience is now for online students, it is still a very individualized (by design) experience. Despite potential online interactions within group work projects and online case discussions, most of the learning is still delivered to each student individually, with no learning spills between students, such as the positive externalities that an in-class learning would facilitate.

Figure 2 describes a framework for online education. We aim to illustrate in Figure 2 the framework that our paper proposes as a complete online education experience. The information content flow is straightforward: information is delivered to the students who then learn it individually and then get tested on it. The information may take the form of online videotaped lectures that can be pre-recorded or recorded live but then delivered asynchronously. It can also consist of office hours online through video-conferencing software (like Zoom 


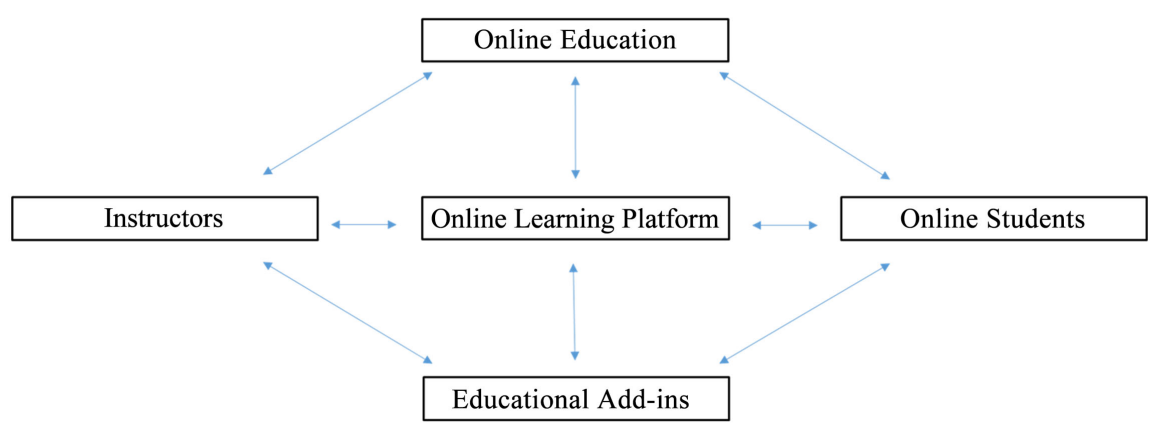

Figure 1. Online education system.

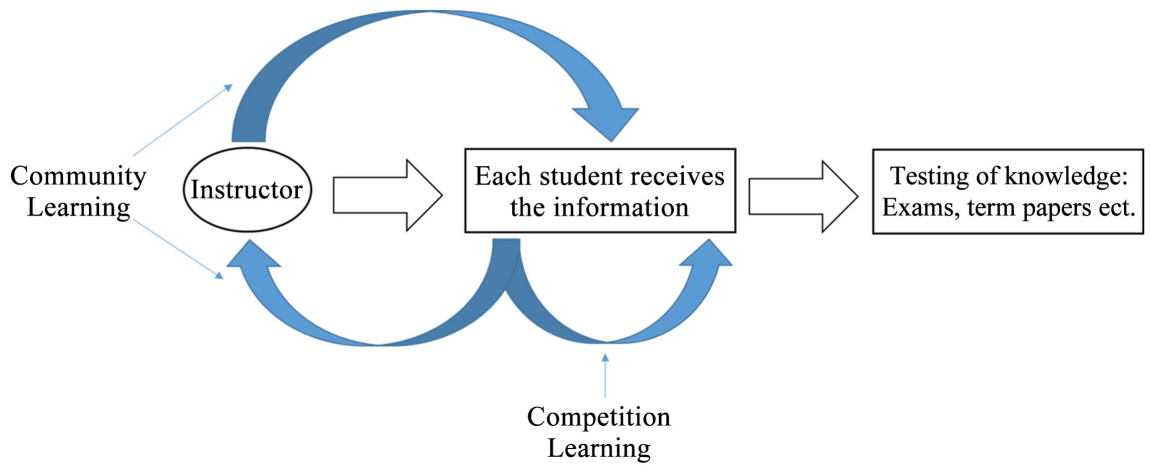

Figure 2. Online education framework.

or Skype). Instructors could also use online video tutorials, online simulations or case interviews to deliver the informational content. The important difference between this type of material delivery and in-class material delivery is that all students receive it individually and remotely.

The testing part of the education system is individualized. Students can take exams online (either un-proctored, but more commonly tests are proctored to ensure rigor), submit homework on the platform (either directly to the online learning platform or thought a third party application that can verify plagiarism across the web, like Turnitin) and also work in a group setting.

Online students value the possibility to control their schedules and learn the content at different times. This is what makes the online programs attractive to the students.

However, it is this feature that will create the boundary of what is learned in the online programs. Because each student is motivated to learn individually, the learning can happen only though modes of learning enabled by the instructor, but students cannot benefit from other students' learning struggles or questions. In Figure 2, we have highlighted these modes of organic learning from peers in dark curved arrows. These are the pieces of leaning that would happen naturally in an in-person class but cannot happen in an online setting unless they are planned and implemented by the instructor.

We identify two types of organic peer-induced learning: community learning and competition learning. These are positive externalities in a network of students engaged in the learning process. 
Community learning is defined as the process through which students engage in deeper learning, communicate their questions to the instructor and the instructor gives the answers and clarifications to the entire class. All students thus learn more about the concepts, from the questions posed and the answers received, even if they were not the ones to initiate the back-and-forth process. The students learn from each other and from the instructor's clarification of the material in response to the community's questions.

Competition learning is a more subtle way of learning from peers. It refers to understanding where a peer is in the learning process and being encouraged to engage in learning to catch-up with that peer. For example, if students in a physical class are given the task to solve a problem, often most of them will start working on the problem right away. The few students who would like to skip the hands-on problem solving task may directly observe the behavior of other students and at least attempt to do the work themselves. In a traditional education setting, students themselves would try to see how they compare with their peers. For example, if they had to deliver a presentation but presence was not mandatory, they may choose to come and see other presentations just to see whether they are doing as well as their peers in delivering the presentation. In an online setting, students would not be able to observe other students' learning behaviors and would miss out on the extra incentive to do the work themselves.

\section{Analysis and Discussion}

It is often the case that instructors will try to deliver an excellent selection of materials to their online students. The technology available now on learning platforms, coupled with third party learning applications can deliver an almost complete learning experience from an information standpoint. In addition, we offer a few suggestions that educators can use to manage the missing organic components of in-class education.

Community building can be achieved by creating an assignment that will allow students to create a short deliverable as a group. Creating a webpage for a local business, for a fictional business page, a Pinterest-like mood board, a wiki with information collected as a group would all be excellent projects. We recommend against assigning a grade for the community building projects. Assigning points or a grade to the deliverable would transform the community building exercise into a chore for the students. Instead, students who work on it will want to do it because they feel proud of being in the class. For an added incentive, it could be used in a restricted public space: perhaps featured on the class webpage, or the course website, or used for a future class, or for future promotional materials for the class.

Competition learning is difficult to facilitate without students who can interact live with each other. Yet, it is important to create it as this is the only incentive that is non-punitive for the students. In a typical grading scheme each missed deliverable comes with a penalty for the students. However, if students 
can see other students working hard, they might also have an incentive to work hard and not miss deliverables. Allowing students to brain-storm in small groups in a Zoom session is a good start to getting them to open up about where they are in the course. Another option is to have a simulation where students can learn and play against each other or with the computer. The score would not count for the students' grade, but the experience of seeing how each individual was doing in the same sort of simulated online game is usually very effective to get students to work hard.

Business courses aim to generate and deliver knowledge and techniques to students who can then apply them in real-life situations. Community and competition learning need to be created by the instructor in order for in-depth thinking and learning to occur. Students can take tests and write papers without fully being able to apply the concepts to real situations if they don't need to defend their ideas in a live discussion with another person. Moreover, it is almost impossible for an instructor to deliver all the information needed for learning if the instructor cannot take into account the areas where the students may need more help or even the areas the students would be most interested in learning. This type of in-depth learning is what business courses aim for, and in an online setting instructors will need to create a way for a community to exist and for students to see each other's work in a way that will help them learn from each other and also make each other learn better.

Our framework is vital for understanding online education, whether it is for a small class of a few hundred students or a massive open online course (MOOC). For smaller classes, the instructor has to create the community and competition learning and can monitor the development of both as described using the examples above. In MOOCS, community and competition learning are harder to implement and use, given the sheer size of the cohorts and also the varying levels of commitment on the students' part. However, it is particularly for this type of large course that the two factors we identify make a big difference for the deep learning needed, as they can incentivize students to work harder and also help them understand the material better. The difficulty of having a single instructor foster these two main factors for many students implies that the instructor has to create sub-communities and allow the students to organize themselves into smaller groups that will naturally interact with each other. One example from online learning would be the Youtube tutorials that many teachers, parents and students post trying to help each other learn a language or difficult science concepts (in the style of the Kahn Academy). Though further research is needed, we believe that the two concepts we identify in this paper, the community and competition learning, can be scaled up for any type of course with the appropriate amount of work and thoughtfulness on the instructor's part.

\section{Conclusions and Future Research}

In this paper, we present a framework for enhancing online business education. We rely on previous research that has established that face-to-face interactions 
can lead to better learning outcomes and to higher student satisfaction with the learning process. We identify two components, community and competition learning that need to be created or facilitated online by the instructor as they won't appear organically as they would in a traditional classroom. Our work is relevant particularly for business classes that need a deeper learning and more hand-on training that traditional humanities or sciences disciplines.

This paper presents a theoretical framework which identifies two new areas that need to be created and facilitated by the instructors of online course. Further research is needed to establish the relative importance of community and competition learning. In particular, experimental research could shed light on the impact of these areas on student learning outcomes.

In depth research is also needed to establish which practices can be most successfully or efficiently implemented in an online classroom. Such in depth research could use direct student data from conjoint studies based on student responses: in an environment where students shop around for classes and face tradeoffs of price, time and learning, perhaps marketing research methods could help design better online classes to balance student learning with student satisfaction.

Another area for further research could focus on flipped classrooms or blended environments. These online-in class education hybrids can potentially yield the best of both worlds, but there is also a potential for larger errors since the students and the instructors have to juggle more components for the education process. More research is needed on how to use the community and competition learning created in the in-class side of the class and leverage them for the overall course efficiently.

\section{References}

[1] BestSchools.org (2018) Best 100 Online Colleges. https://thebestschools.org/rankings/best-online-colleges/

[2] BestSchools.org (2018) Best 50 Online MBA Programs. https://thebestschools.org/rankings/best-online-mba-programs/

[3] Gault, J., Redington, J. and Schlager, T. (2000) Undergraduate Business Internships and Career Success: Are They Related? Journal of Marketing Education, 22, 45-53. https://doi.org/10.1177/0273475300221006

[4] Mitchell, J. (2018) The Rise of the Jumbo Student Loan. https://www.wsj.com/articles/jumbo-loans-are-new-threat-in-u-s-student-debt-mar ket-1518790152

[5] Hollenbeck, C.R., Mason, C.H. and Song, J.H. (2011) Enhancing Student Learning in Marketing Courses: An Exploration of Fundamental Principles for Website Platforms. Journal of Marketing Education, 33, 171-182. https://doi.org/10.1177/0273475311410850

[6] Giesbers, S., Rienties, B.C., Gijselaers, W.H., Segers, M. and Tempelaar, D.T. (2009) Social Presence, Web-Videoconferencing and Learning in Virtual Teams. Industry and Higher Education, 23, 301-310.

[7] Buzzard, C., Crittenden, V., Crittenden, W. and McCarty, P. (2011) The Use of Dig- 
ital Technologies in the Classroom: A Teaching and Learning Perspective. Journal of Marketing Education, 33, 131-139. https://doi.org/10.1177/0273475311410845

[8] Northey, G., Bucic, T., Chylinski, M. and Govind, R. (2015) Increasing Student Engagement Using Asynchronous Learning. Journal of Marketing Education, 37, 171-180.

[9] Dillenbourg, P. (1999) Collaborative Learning: Cognitive and Computational Approaches. Advances in Learning and Instruction Series. Elsevier Science, Inc., New York, NY.

[10] Gokhale, A.A. (1995) Collaborative Learning Enhances Critical Thinking. Journal of Technology Education, 7.

[11] Johnson, R.T. and Johnson, D.W. (1986) Action Research: Cooperative Learning in the Science Classroom. Science and Children, 24, 31-32.

[12] Keppell, m., au, e., ma, a. And chan, c. (2007) Peer Learning and Learning-Oriented Assessment in Technology-Enhanced Environments. Assessment \& Evaluation in Higher Education, 31, 453-464. https://doi.org/10.1080/02602930600679159

[13] Bishop, J. (2006) Chapter 15 Drinking from the Fountain of Knowledge: Student Incentive to Study and Learn-Externalities, Information Problems and Peer Pressure. In: Hanushek, E. and Welch, F.., Eds., Handbook of the Economics of Education, Elsevier, Amsterdam, Vol. 2, 909-944. https://doi.org/10.1016/S1574-0692(06)02015-0

[14] Boud, D., Cohen, R. and Sampson, J. (1999) Peer Learning and Assessment. Assessment \& Evaluation in Higher Education, 24, 413-426.

[15] Boston University Online Education 2018. https://www.bu.edu/online/about-us/

[16] University of Florida Online Education 2018. https://ufonline.ufl.edu/about-us/ 